\title{
Research on the Application of "Duifene" Teaching Platform in the Course of Kindergarten Multimedia Courseware Production
}

\author{
Xiaoli Zhao \\ Linyi University \\ Linyi, China
}

\begin{abstract}
Multimedia courseware production is an important part of modern educational technologies, and it is also the main embodiment of computer-aided teaching and an important aspect of the informatization of education. To cultivate the ability of preschool teachers to design and produce multimedia courseware has become an important task for preschool education speciality. However, in the current "Kindergarten Multimedia Courseware Production" class, students' lack of initiative in learning, poor self-control, and other problems have led to the inefficiency of the classes. Taking the "Kindergarten Multimedia Courseware Production" course as an example, this paper expounds how to overcome the shortcomings of the current classes by using the "duifene" teaching platform, make classes efficient, and cultivate students' independent learning ability and innovative ability.
\end{abstract}

Keywords-pad class; "duifene" teaching platform; kindergarten multimedia courseware production; teaching reform

\section{INTRODUCTION}

The "Professional Standards for Preschool Teachers (Trial)" promulgated by the Ministry of Education on February 10, 2012 stipulates that preschool teachers must "have certain knowledge of modern educational technologies". Multimedia courseware production is an important part of modern educational technologies, and it is also the main embodiment of computer-aided teaching and an important aspect of the informatization of education. Researches show that the multimedia teaching which integrates figures, texts, sounds and images is more in line with the cognitive rules of young children and the characteristics of kindergarten teaching. Therefore, to cultivate the ability of preschool teachers to design and produce multimedia courseware has become an important task of preschool education speciality. This project is the reform of the classroom teaching model, which is based on the previous trial reform of the "Computer Culture Foundation" course, based on the principle of employment orientation, fully taking into account the cognitive rules of students and the characteristics of the subject, focusing on the development of information technologies especially multimedia technology and the actual needs of kindergarten teaching. Solve the problem of students' lack of interest in this course by applying a new online teaching mode. This new teaching mode emphasizes bisection teaching, flexibly guides students to actively participate in the process of learning, and makes good use of the duifene network platform to implement the teaching mode of "autonomy-cooperation-innovation", fully develop students' personalities in various learning activities, and cultivate learners' innovative spirit and practical ability.

\section{THE CONNOTATION OF THE BISECTION ClASSROOM TEACHING MODE}

The bisection classroom teaching mode combines the traditional lecture-style class and the discussion-style class, and advocates that teacher teaching and student discussion respectively take up half of the class. The specific proportion can be adjusted according to different teaching contents and learning effects. This teaching mode emphasizes "internalization absorption", and combines teacher teaching and student discussion creatively through "internalization absorption", forming three stages of bisection classes: teaching, internalization and discussion.

\section{Module Composition OF THE "DuIFENE" TEACHING PLATFORM}

\section{A. The Composition of the "Duifene" Teaching Platform}

The "duifene" teaching platform is the practice result of bisection classes, which provides a powerful means for the realization of the bisection classes. On the duifene network teaching platform, the class is established by the teacher first, and the students can join the class by scanning the QR code; for each class, the teacher will send its QR code, the students can enter the class by scanning the WeChat QR code or login with their accounts. Attendance record can be completed in a few seconds, which saves much time compared to the traditional attendance record method; the platform's automatically saving attendance records provides a basis for students' usual attendance. The platform includes various modules such as attendance module, course resource module, grouping module, homework module, discussion area, WeChat message, grade book, in-class question, questionnaire, voting activity, and teaching evaluation. Students and teachers can apply these modules to separately realize teaching resource upload, homework download, group competition, class answering, after-school evaluation, and WeChat answering. 


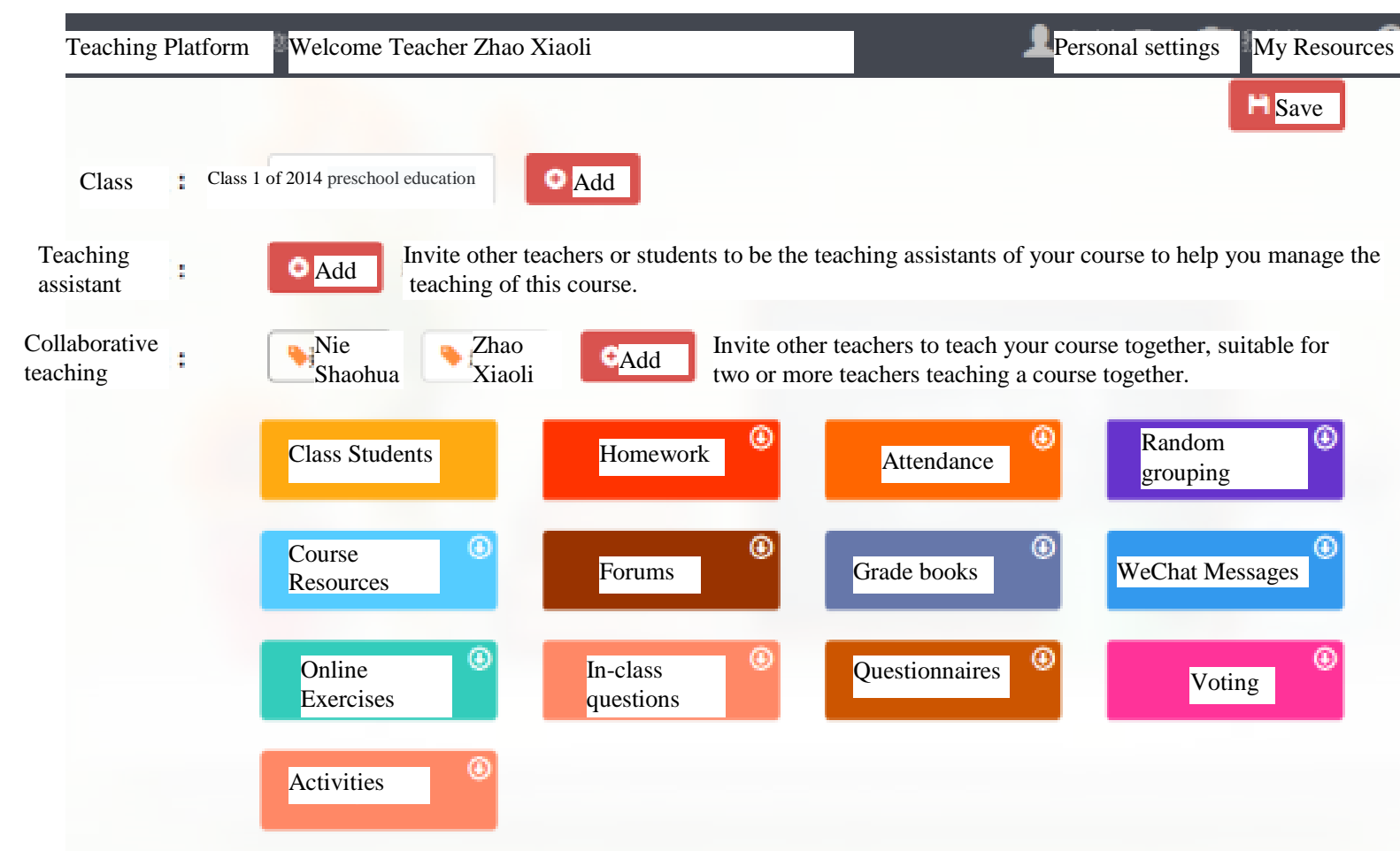

Fig. 1. Teaching platform interface.

1) Class student module and attendance module: After the student has scanned the QR code of the class using the mobile phone, he will be a member of the class established by the teacher. The students whose classes have changed can move between classes. When the teacher records the attendance, he should first set the time reserved for the students to scan the QR code, start timing when the attendance QR code is sent to students, and the students open the "WeChat scan code" function to scan the code. After the code is successfully scanned, the attendance records of students will be automatically displayed and stored by the platform.

2) Course Resource Module: The course resource module supports various kinds of documents. The course content is presented in the "modular" and "project-based" methods, which not only reflects the stepwise feature from simple to complex, but also reflects the relatively independent and selfcontained systematic characteristic. The courses are uploaded and saved to the course resource module. In addition to the teaching resources provided by the teachers, students can upload excellent learning resources acquired in the learning process to the course resource module after the resources have passed the teachers' reviews, such as micro-courses and excellent cases.

3) Homework module: If the teacher releases the homework in the homework module, the students will receive the message pushed by the platform on WeChat. In this module, the teacher has the right to set the time limit for students to finish the homework. If the students complete the homework within the limited time, they can upload it. Otherwise, they cannot upload it.

4) Three interesting modules: The discussion area module, the in-class question module and the voting module are the three interesting modules on the duifene teaching platform. The discussion area supports the instant class discussions; in the in-class question module, the teacher can name students to answer the questions, and students can also answer the questions on the mobile phones; through the questionnaire survey, it is found that the students like to use this answering method. Voting is also one of the activities students like, and it is usually used in the evaluation of works.

5) Teacher-student interaction module: Questionnaire module and WeChat message module provide teacher-student interaction function. The questionnaire module supports various kinds of questions, teachers can freely set up class evaluation questions, students can $\log$ in to the platform to answer these questions at any time. The WeChat message module supports instant communication to ensure that teachers have an accurate understanding of the learning effects and can more accurately design the next teaching session.

The modularization of the duifene platform realizes the long-term storage of resources and learning effects. The modules are both independent and systematic, which can meet the selectivity and autonomy of learners, and is suitable for students to accumulate learning resources and works to prepare for the future work. 


\section{THE COURSE REFORM EFFECTS OF THE "DUIFENE" TEACHING PLATFORM}

\section{A. Traditional Teaching Effects}

Preschool education students, influenced by the characteristics of the speciality, are weak in abstract thinking ability and generalization analysis ability, are relatively strong in image thinking ability and imitation and application ability. They are not good at understanding abstract things, and can easily accept visual, specific things. In traditional teaching, students' weak abstract thinking ability has led to their low interest in learning this course. Teachers play the "protagonists" in the classes, and students are not efficient in learning. Without the active cooperation of students, the flexibility of the class is lost, and it is difficult to develop students' innovative and collaborative abilities. The class evaluation is not timely or just a form.

\section{B. Teaching Practice Effects of the "Duifene" Teaching} Platform

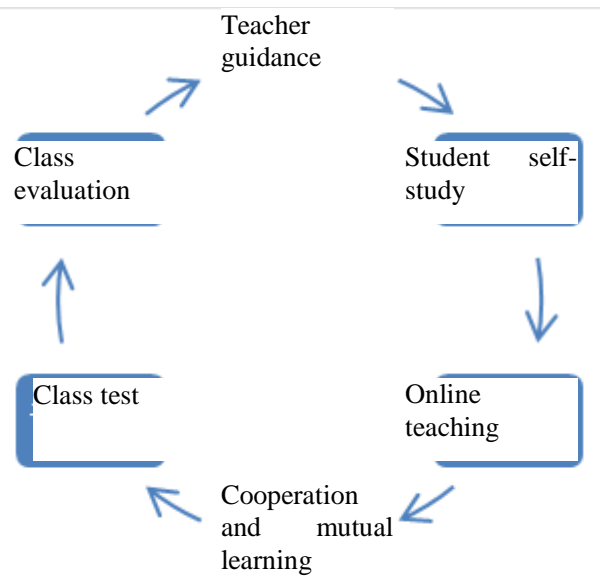

Fig. 2. Teaching link diagram.

Students are more interested in the cases of courseware production, accepting faster, and resentful of abstract theoretical teaching. In view of this feature, the problem is solved by applying the duifene teaching platform. The class is divided into six stages, teacher guidance, student self-study, online teaching, collaborative learning, class testing, and class evaluation.

1) Determine learning content and discover defects of own knowledge: According to the requirements of the syllabus of courses such as "Kindergarten Multimedia Courseware Design and Production", multimedia courseware is produced according to the textbook chapters, the overall objective of the course is determined and the specific subgoals are determined according to the chapters. The sub-goals are closely related to the specific learning contents. The determination of sub-goals is an important basis for achieving the overall goal. The chapter goals and learning contents are uploaded to the duifene teaching platform in advance. The learners can evaluate their knowledge status according to the learning tasks, objectively recognize their own knowledge defects, form learning needs based on the self-evaluation information, and identify the resources that can meet these needs.

2) Upload learning resources before class to achieve classroom halving: The teacher provides video and audio learning resources corresponding to the content of the "Kindergarten Multimedia Courseware Production". Instructional videos can be recorded by the instructor personally or using high-quality online open resources. First of all, the teacher clarifies the teaching objectives, key points and difficulties, and guides the students to have purposeful learning. After the teacher teaches the knowledge points or the students finish reading the teaching resources, the harvest and questions in the video shall be recorded and then, it's better to carry out discussion and exchange about the solutions to teacher normative issues through the teaching platform named "duifene".

3) Determine the basic structure of the group, realize cooperative and mutual learning, and reserve adjustment space: Practice has shown that the studying effect for students learning in a cooperative group with a good organizational structure is far better than that in traditional form of class organization. When students start to learn, they often lack the means of cooperation and independent exploration. Therefore, it's better for students to grasp knowledge by forming and executing learning plan according to the free group or grouping and meeting the learning needs in a complementary way. In the course of practice, the free combination of grouping and random grouping should be tried separately. The free combination group is more humanized, taking care of the students' interpersonal relationship, and making the cooperation more free and easy, but there may be strong alliances, and its complementarity is insufficient; the random grouping method is performed according to the system allocation combination, which can not play the students' original interpersonal relationship, but it can enhance students' ability to accept and unite new partners, which is conducive to reflecting the complementarity of the classroom.

4) Reasonable design of information resources: Cooperative learning requires not only teachers to provide reasonable course resources, but also a large amount of other information resources. In order to improve the efficiency of collaborative learning and shorten the invalid time, teachers upload some resources such as micro-courses and learning materials to the curriculum resource modules of the "duifene" platform. Students can decide when to download and apply these materials according to the actual learning time and needs. Resources provided by teachers are oriented in the direction of "modularization" and "project type". The content of the course and the relatively independent course content are presented step by step in the form of micro-courses, which not only realizes the modular learning of the course, but also guarantees the task-type learning of the course and not only ensures the efficiency of learning, but also inspires the selfmotivation of students. 
5) Give full play to the role of classroom racing answer function and school assignment time-limit function: For the statue that students are not motivated to answer questions, it's beneficial to use the racing answer function of the "duifene" platform to adopt racing answer mechanism, which not only scores according to the excellence of answering questions, but also according to the number of times of racing answer. All these scores will be included into the usual grades of the course at the end of the term. The operation module of the "duifene" platform has a record and WeChat notification for each published job, and the students in the "duifene" platform can receive the notification as soon as the mobile phone is connected to the network. The teacher has the authority to set the time limit for submitting the job. If the job submitted after the set time is submitted successfully, the function is applied to some unactive students to ensure that the task is completed within the specified time. According to the time and quality evaluation submitted, the teacher votes, displays, comments, and scores the excellent homework and works, and counts them into the usual results.

6) Student assessment is more timely and humane, and teachers get more quick comment results: In the classroom evaluation module of the "duifene" network teaching platform, the teacher freely sets the classroom evaluation topic, and the student can answer the questions and make his own evaluation on the "duifene" platform by using the mobile phone or the computer anytime and anywhere. After class, teachers can easily see anonymous student evaluations and be able to understand student problems in a timely manner. What's more, it is easy for teachers to interact with students timely on the "duifene" platform so as to have an accurate understanding of the learning effects of this session, and have more accurate grasp of study plans for the next link. In the evaluation of teaching, especially the evaluation of students on the teacher, the "duifene" teaching platform eliminates the shortcomings of lags and inconvenience of the traditional teaching evaluation method.

7) Group works evaluation and study report highlight course characteristics: Regardless of the method used to teach, students always need a process of digestion for knowledge.So,it's right to design one or two comprehensive assignments per chapter, and give students a one-week completion time. The homework only designs themes and does not design details, which aims to allow students to collect or create multimedia materials such as pictures, audio, video, etc., to cultivate students' innovative ability, and to explore the breadth and depth of divergent thinking. The group assignments are submitted to the group operation of the "duifene" teaching platform. Each class selects a representative to display, explain, and report the completion process, and team scores will be given according to the time of completion and the quality of the work.

\section{CONCLUSION}

The "Kindergarten Multimedia Courseware Production" course involves a lot of contents, which include both software and theories, and some students with weak foundations will be particularly hard at learning software. The introduction of the "duifene" teaching platform helps teachers make full use of the advantages of multimedia to promote students to overcome learning difficulties. In the classroom, it's necessary to assign times of teaching of lecturers and interactive learning of students with the rate about 1:1. Staggering the time of teaching and discussion aims to let students reserve time to arrange self-learning after class to achieve personalized internalization. The students report the assignments in group and the teachers make comments, which greatly improve classroom efficiency. Compared with the traditional classroom, the introduction of halving classroom of the "duifene" teaching platform helps to promote the substantive transformation of the role of teachers and students. The teacher outlines the explanation, combs the knowledge framework, and gives the internalization to the students. In discussion class, the teachers participate in the class and become instructors, increasing the opportunity to communicate emotionally with students. Students are freed from passive lectures. They are encouraged to elaborate and debate, express their own ideas, and complete the absorption of knowledge in a harmonious atmosphere, which makes ready for the later report. This type of class increases the confidence and courage of the students, and realizes a virtuous circle of teaching and learning. Finally, an ecological classroom by the network teaching platform will be constructed.

\section{REFERENCES}

[1] Zhang Xuexin edits,Halving Classroom: New Wisdom in Chinese Education[M].Science Press,2017. 张学新主编, 《对分课堂: 中国教 育的新智慧》 [M].科学出版社,2017

[2] Zhu Zhiting, Educational Technology and Educational Innovation [M] Higher Education Press, 2011 祝智庭,教育技术与教育创新[M].高等 教育出版社, 2011

[3] Li Ming, Construction and Practice Research of "CooperativeExploration" Teaching Model Based on Moodle Platform[D]. Henan University,2011. 李明,基于 Moodle 平台的“合作一探究”教学 模式构建与实践研究[D].河南大学,2011

[4] Zhang Lu, Long Rong, Application of the "Duifene" Platform in the Teaching Interaction of "Basic Medical Generality"[J].Computer Knowledge and Technology,2017,13 (25):92-93 张璐、龙榕,对分易 平台在《基础医学概论》教学交互中的运用实践 $[\mathrm{J}]$. 电脑知识与技 术, 2017,13 (25) :92-93

[5] Liu Juanjuan, Feasibility Analysis of the Application of the Halving Classroom in the Intermediate Financial Accounting Course[J].Higher Education Online,2017,12:155-156 刘娟娟,对分课堂在中级财务会计 课程中应用的可行性分析[J]. 高等教育在线,2017,12:155-156

[6] Zhang Xuexin, Halving Classroom:New Exploration of College Classroom Teaching Reform[J].Fudan Education Forum,2014,12(5):510. 张学新,对分课堂: 大学课堂教学改革的新探索 $[\mathrm{J}]$.复旦教育论 坛, 2014,12(5):5-10.

[7] Che Ping, Yue Geni, Realization of Knowledge Internalization Process of Halving Classroom Based on "Duifene" Teaching Platform[J].Industrial \&Science Tribune, 2017,(16),4:174-175 车乒,岳 格妮,基于 “对分易” 教学平台的对分课堂知识内化过程实现 $[\mathrm{J}]$. 产 业与科技论坛, 2017,(16),4:174-175.

[8] http://dwz.cn/duifenrenhttp://dwz.cn/duifenren 